\title{
Fabrication of silica-based three-dimensional structures by changing fluence using proton beam writing
}

\author{
R. Tsuchiya and H. Nishikawa \\ Dept. of Electrical Engineering, Shibaura Institute of Technology \\ 3-7-5 Toyosu, Koto-ku, Tokyo 135-8548 \\ "Phone: +81-3-5859-8217, Fax: +81-3-5859-8201, E-mail: nishi@ sic.shibaura-it.ac.jp
}

\begin{abstract}
We performed micromachining of relatively thick siloxane films by proton beam writing (PBW) with beam energy of $1 \mathrm{MeV}$. The polydimethylsiloxane (PDMS) prepolymer films with a thickness of about $13 \mu \mathrm{m}$ were spin-coated onto silicon substrates. After exposure to the $1-\mathrm{MeV}$ proton beam $(\sim 1 \mu \mathrm{m}$ in diameter), the samples were developed. The PDMS shows the behavior of negative resist and can be regarded as analog resist where the thickness of the structure gradually increases as a function of the proton beam (PB) fluence. Using this feature of the PDMS, we manufactured micro lenses with diameter of $40 \mu \mathrm{m}$ by changing PB fluence. Micro-patterning of the PDMS films using scanning proton beam can offer a possibility of making three-dimensional structures for silica-based devices without baking and mask process.
\end{abstract}

Key word: siloxane, proton beam writing, polydimethylsiloxane, micro lens

\section{INTRODUCTION}

In recent years, rapid progress has been made in the development of optical devices for memory and interconnect. In the field of the optical devices, we need decreasing coupling loss and downsizing of devices. Up to now, several ideas to produce optical devices such as micro lenses were reported ${ }^{[1-4]}$. Generally, silica is a material of choice for these devices due to the high transparency and good mechanical properties. However, because of the fact that conventional prototyping techniques for silica-based optical devices require several processes including photolithography, dry etching etc., the cost is expected to be high.

We have previously reported a micro-patterning of a relatively thin organic and inorganic siloxane films such as Methyl Silsesquioxane (MSQ) and Hydrogen Silsesquioxane (HSQ), both exhibiting the characteristics of negative resists ${ }^{[5]}$. However, since the thickness of these films was limited to less than $1 \mu \mathrm{m}$, the deep micromachining feature of the proton beam writing (PBW) was not fully utilized for potential optical applications, such as micro lenses and planar waveguides.

In this paper, we performed micromachining of relatively thick siloxane films of more than $10 \mu \mathrm{m}$ by PBW with beam energy of $1 \mathrm{MeV}$ to simplify the processing steps and to produce flexible silica-based optical devices.

PBW is a promising method for micro-fabrication by direct writing using a focused beam of $\mathrm{MeV}$ protons, since the MeV-order proton beam has several advantages over other sources such as electrons and photons. First, the scattering of the proton is small when compared with electrons penetrating into the same depth. Secondly, the projected range of the protons can be controlled with the beam energy. It is useful for the fabrication of high aspect ratio structures and prototyping of devices ${ }^{[6-8]}$.

Siloxane refers to chemical compounds composed of $\mathrm{Si}-\mathrm{O}-\mathrm{Si}$ bonds. Since the siloxane is sensitive to irradiation by energetic particles of electrons and ions, micro-patterning of the siloxane film by these irradiation is promising technique to fabricate silica-based optical devices ${ }^{[9,10]}$.

In this study, we use PDMS (polydimethylsiloxane) to obtain thick prepolymer films suitable for PBW. Fig.1 shows the structure of PDMS. Due to the fact that PDMS is optically clear, chemically inert and stable, non-toxic

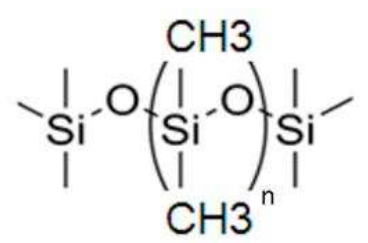

Fig.1. Structure of PDMS 
and biocompatible material it is usually used for the production of numerous active and passive implant devices and optical waveguides or microlenses.

\section{EXPERIMENTAL}

We used PDMS prepolymer for fabrication silica-based three-dimensional structures using PBW. The PDMS (Dow Corning: Sylgard184) consists of base liquid (prepolymer) and curing agent for polymerization. In this study, we used only the base prepolymer liquid spin coated on a substrate to expose for polymerization by PBW.

The PDMS films with a thickness of about $13 \mu \mathrm{m}$ were spin-coated onto $10 \times 10 \mathrm{~mm}^{2}$ silicon substrates for 60 $\mathrm{sec}$ at $8000 \mathrm{rpm}$. After exposure to PB, PDMS films were developed with a solution of tetrahydrofuran (THF)- $\mathrm{CH}_{3} \mathrm{CN}$ (8:2) mixture for $2 \mathrm{~min}$.

The PBW was performed using a proton beam writer (Kobe Steel Corp., MB-S1000) at beam energy of 1.0 $\mathrm{MeV}$. After development, these samples were observed by the Scanning Electron Microscope (SEM, Shimadzu, SSX-550) and Confocal Laser Microscope (OLYMPUS, LEXT OLS4000). We also measured micro-Raman and FT-IR spectra on the PB-exposed area to analyze change in the local chemical bonding.

SRIM ${ }^{[11]}$ calculations show that the projected range of 1.0 MeV protons is $\sim 29 \mu \mathrm{m}$ into PDMS. Although the range is larger than the thickness of $13 \mu \mathrm{m}$ PDMS film on silicon substrate, no deformation of the silicon surface due to implanted protons was observed by SEM at the present PB fluence.

\section{RESULTS AND DISCUSSION}

\subsection{Raman and FT-IR measurements}

Figs. 2 (a) and (b) show Raman and FT-IR spectra obtained before and after exposure to $1.0 \mathrm{MeV} \mathrm{PB}$ for PDMS films up to the fluence of $1.0 \mu \mathrm{C} / \mathrm{mm}^{2}$. The Raman spectra show decreasing peaks at $2910 \mathrm{~cm}^{-1}$ and $2960 \mathrm{~cm}^{-1}$, which correspond to $-\mathrm{CH}_{3}$ bond in $\mathrm{CH}_{3}-\mathrm{Si}$. The FT-IR spectra show increase of the peak at $1015 \mathrm{~cm}^{-1}$ and decrease of the peak at $1075 \mathrm{~cm}^{-1}$ which indicate the decrease of Si-O-Si short chain and increase of Si-O-Si long chain, respectivery. Both changes in the local chemical bonding show the scission at $\mathrm{Si}-\mathrm{CH}_{3}$ bonds by $\mathrm{PB}$ in the PDMS film and formation of $\mathrm{Si}-\mathrm{O}-\mathrm{Si}$ networked structure ${ }^{[12,13]}$.

Based on these observations, we expect the following reaction in Fig.3, where $-\mathrm{CH}_{3}$ bonds were broken by irradiation with $\mathrm{PB}$ and react with $\mathrm{H}_{2} \mathrm{O}$ to form Si-O-Si network. The role of $\mathrm{H}_{2} \mathrm{O}$ in the scheme of Fig. 3 is to drive the methyl group out of the Si-O-Si network in the form of methyl alcohol. Since the reaction requires $\mathrm{H}_{2} \mathrm{O}$ in the PDMS films, it is suggested that the $\mathrm{H}_{2} \mathrm{O}$ uptake into the PDMS prepolymer must be important to control the reaction scheme in Fig. 3.

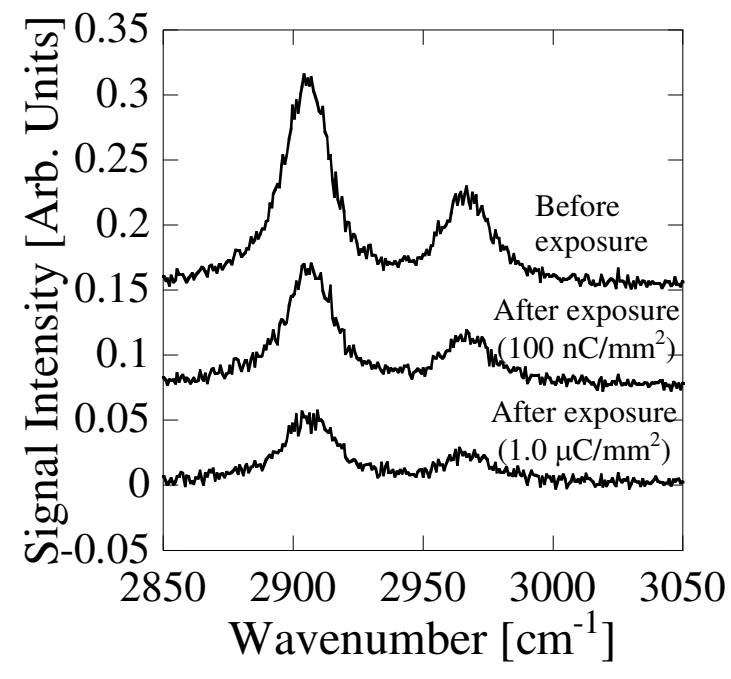

(a) Raman spectra

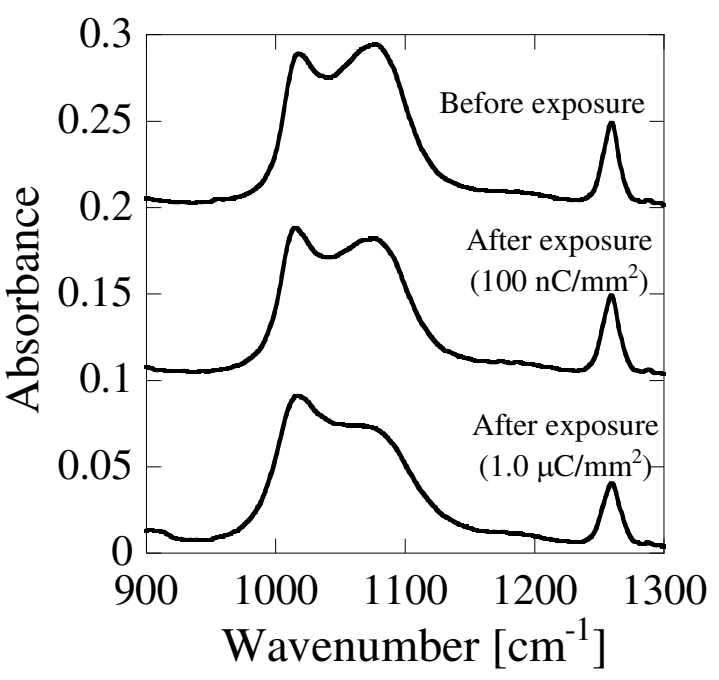

(b) FT-IR spectra

Fig. 2. Raman and FT-IR spectra obtained before and after exposure with $1.0 \mathrm{MeV}$ proton beam at the fluence of $100 \mathrm{nC} / \mathrm{mm}^{2}$ and $1.0 \mu \mathrm{C} / \mathrm{mm}^{2}$ for PDMS films.<smiles>CO[Si](C)(C)CCO[Si](C)(C)C</smiles>

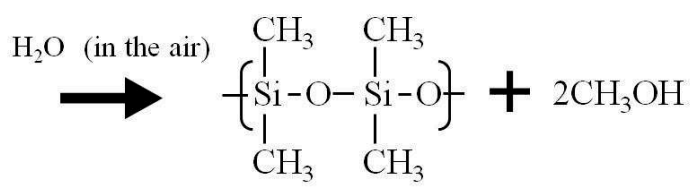

Fig. 3. The reaction of PDMS prepolymer exposed to $\mathrm{PB}$ involving $\mathrm{H}_{2} \mathrm{O}$. 
3.2 Fluence modulation of PBW on PDMS

Fig. 4 shows a SEM image obtained for PDMS films which was scanned with $6 \times 6$ arrays of squared patterns with $1.0 \mathrm{MeV} \mathrm{PBW}$ at various fluences from $1.0 \mathrm{nC} / \mathrm{mm}^{2}$ to $300 \mathrm{nC} / \mathrm{mm}^{2}$.

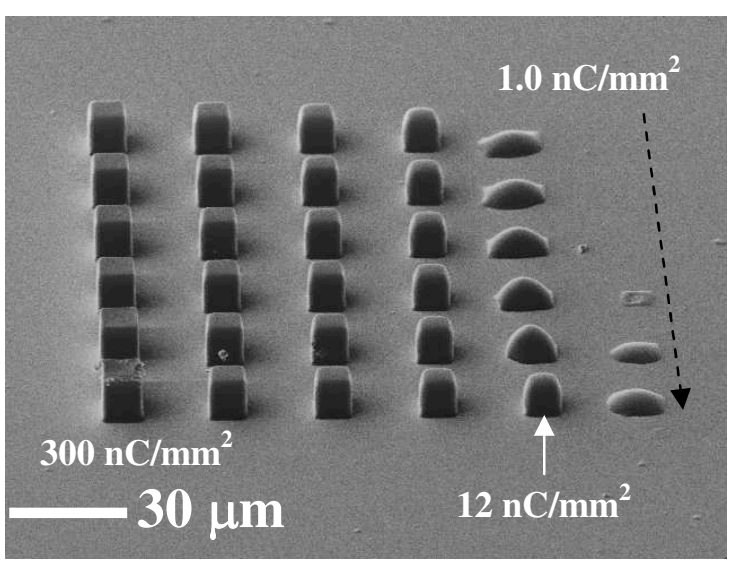

(a) SEM image after development

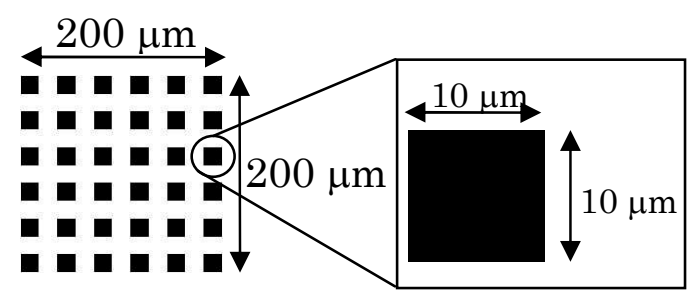

(b) Squared patterns scanned by PBW

Fig. 4. (a) SEM image of a PDMS film after development which was scanned with (b) $6 \times 6$ arrays of squared patterns by $\mathrm{PB}$.

The squared pattern was produced at fluences starting from $4 \mathrm{nC} / \mathrm{mm}^{2}$. The curved surfaces observed at low fluence were changed to cubic structures with upright side surfaces around $12 \mathrm{nC} / \mathrm{mm}^{2}$.

Fig. 5 shows the thickness of the remaining structures in Fig. 4 plotted as a function of the fluence of PB. The thickness of the PDMS structures gradually increases

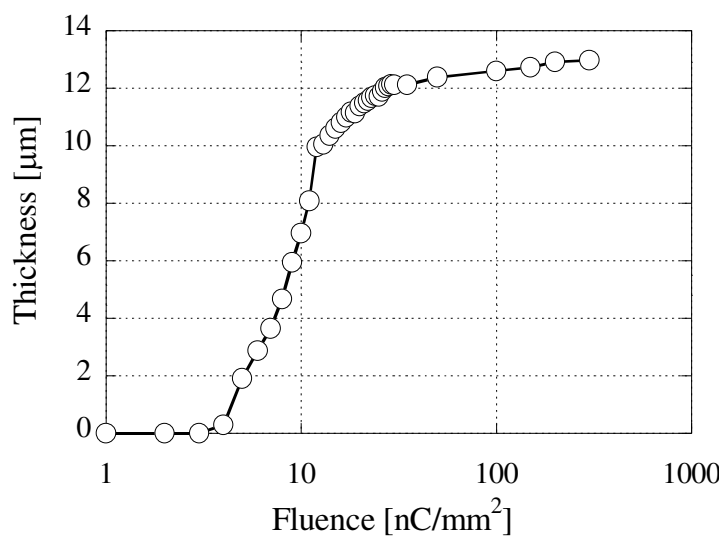

Fig. 5. Remaining film thickness of PDMS films as a function of the fluence of $1.0 \mathrm{MeV}$ PB.

with increasing PB fluence from 1.0 to $300 \mathrm{nC} / \mathrm{mm}^{2}$. Contrast $\gamma$, which is defined by $\gamma=\left[\ln \left(\mathrm{F}_{100} / \mathrm{F}_{50}\right)\right]^{-1}$ is estimated to be 1.34 from the values of $F_{100}: 20 \mathrm{nC} / \mathrm{mm}^{2}$ and $\mathrm{F}_{50}: 9.5 \mathrm{nC} / \mathrm{mm}^{2}$ obtained from Fig. 5. The $F_{100}$ and

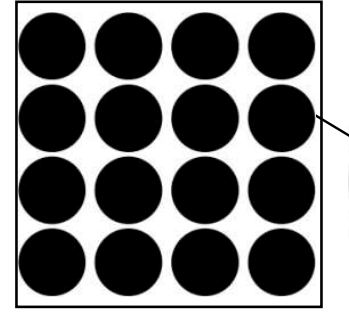

High

Fluence

Low

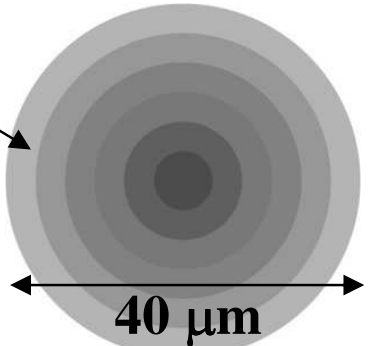

$10 \mathrm{nC} / \mathrm{mm}^{2}$

$9.0 \mathrm{nC} / \mathrm{mm}^{2}$ $8.0 \mathrm{nC} / \mathrm{mm}^{2}$ $7.0 \mathrm{nC} / \mathrm{mm}^{2}$ $6.0 \mathrm{nC} / \mathrm{mm}^{2}$ $5.0 \mathrm{nC} / \mathrm{mm}^{2}$

Fig. 6. The method of changing fluence to produce curved PDMS surface by PBW.

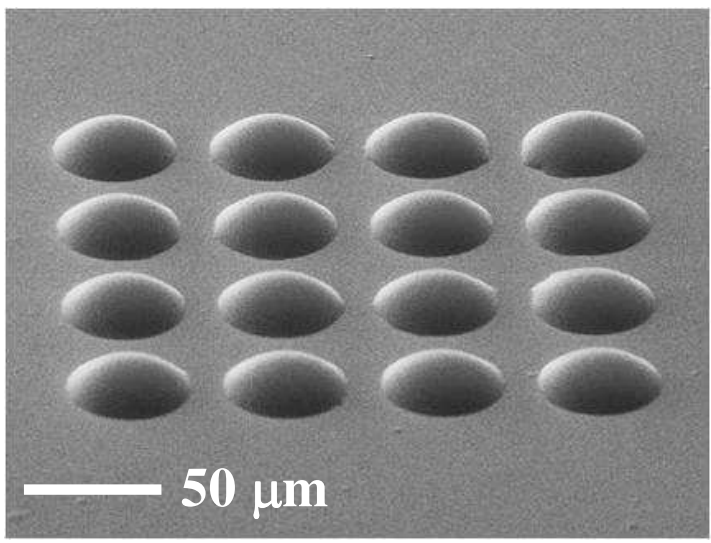

(a) Overall image

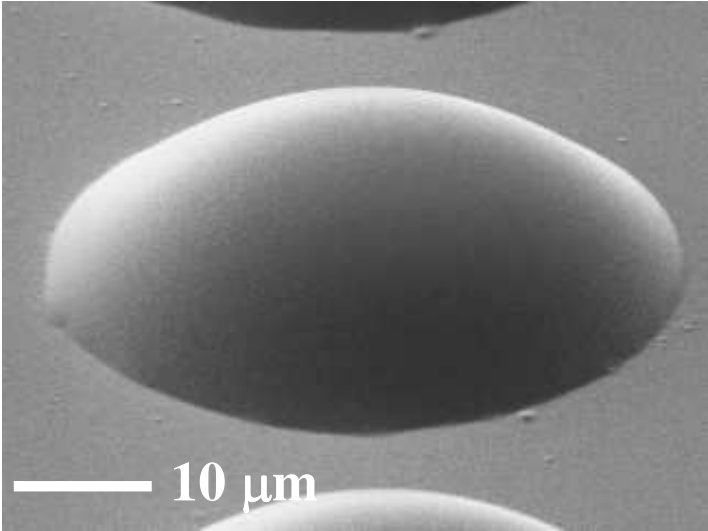

(b) Magnified image

Fig.7. The SEM images of a curve surface after development for the PDMS film by PBW under the condition shown in Fig.6. 
$\mathrm{F}_{50}$ represent, respectively, the fluence at which the film is fully insoluble to developer and the one at which the thickness is $50 \%$ of the original thickness. The value of $\gamma$ is comparable to that reported for siloxane films exposed to $\mathrm{EB}{ }^{[14]}$. Therefore, we can conclude that the PDMS prepolymer shows the behavior of an analog resist.

The analog resist feature of PDMS prepolymer shown in Fig. 5 suggests that the height of the PDMS structure can be controlled by PB fluence. We can apply the feature to produce silica based optical elements with curved surface structure such as micro lens. The curved surface can be obtained by increasing the PB fluence gradually from the outer edge to the center of circles, as shown in Fig. 6.

Fig.7 shows the SEM image obtained by PBW with changing fluence shown in Fig. 6. A smooth curved surface aimed for micro lens with a height of $10 \mu \mathrm{m}$ and diameter of $40 \mu \mathrm{m}$ was obtained.

\section{SUMMARY}

A $13 \mu \mathrm{m}$ thick PDMS prepolymer film was studied for micro-patterning using 1-MeV proton beam. Raman and FT-IR spectra measurements show the PDMS prepolymer was cross-linked to form Si-O-Si network by exposure to PB. The PDMS exhibits a feature of a negative resist with gradually changing thickness as a function of PB fluence. Using this feature, a smooth curved surface has been obtained for PDMS. We demonstrated that application of the PDMS prepolymer for PBW is useful in prototyping silica-based optical device.

\section{REFERENCES}

[1] T-K Shih, Chia-Fu Chen, Jeng-Rong Ho, Fang-Tzu Chuang, Microelectronic Engineering 83 (2006) 2499-2503

[2] $\mathrm{M}-\mathrm{H} \mathrm{Wu}$ and G.M. Whitesides, J. Micromech. Microeng. 12 (2002) 747-758

[3] Zoran D. Popovic, Robert A. Sprague, and G. A. Neville Connell, Applied Optics 27 (1988) 1281-1284

[4] N. Chronis, G. L. Liu, K-H Jeong, and L P. Lee, Optics Express 11 (2003) 2370-2378

[5] H. Nishikawa, R. Tsuchiya, T. Yasukawa, T. Kaneko, Y. Furuta, and T. Ohishi, J. Photopolym. Sci. Technol., 22 (2009) 239-243

[6] Frank Watt, Mark B. H. Breese, Andrew A. Bettiol, and Jeroen A. van Kan, Material Today 10 (2007) 20-29

[7] N. Uchiya, T. Harada, M. Murai, H. Nishikawa, J. Haga, T. Sato, Y. Ishii, T. Kamiya, Nucl. Instrum. and Meth. in Phys. Res. B260, (2007) 405-408.

[8] Y. Furuta, N. Uchiya, H. Nishikawa, J. Haga, T. Sato, M. Oikawa, Y. Ishii, T. Kamiya, J. Vac. Sci. Technol. B 25 (2007) 2171-2174.
[9] J.A. van Kan, F. Zhang, C. Zhang, A.A. Bettiol, F. Watt, Nucl. Instr. and Meth. in Phys. Res. B 266 (2008) 1676-1679

[10] S.Z. Szilasi, R. Huszank, A. Csik, C. Cserháti, I. Rajta, Nucl. Instrum. and Meth. in Phys. Res. B 267 (2009) 2296-2298

[11] J. F. Ziegler, SRIM2008, http://www.srim.org/

[12] K. Efimenko, W. E. Wallace, and J. Genzer, J. Colloid Interface Sci. 254 (2002) 306-315

[13] C. Y. Wang, Z. X. Shen, and J. Z. Zheng, Applied Spectroscopy, 54 (2000) 209-213

[14] Y Sakurai, K. Satoh, H. Fukuda, T. Yotsuya, Y. Suzuki, J. Soc. Mat. Sci. Japan 52 (2003) 1425-1429 (in Japanese)

(Received February 9, 2011; Accepted May 31, 2011) 